\title{
OXIDATION OF PYRUVATE AND GLUCOSE BY OOCYTES OF THE MOUSE AND RHESUS MONKEY
}

\author{
R. L. BRINSTER \\ Laboratory of Reproductive Physiology, The School of Veterinary Medicine, \\ University of Pennsylvania, U.S.A.
}

(Received 10th March 1970)

Summary. Garbon dioxide formed by the mouse oocyte from glucose was $0.145 \mathrm{pmol} / \mathrm{hr} /$ oocyte, which is the same as the value previously found for unfertilized mouse ova. Carbon dioxide formed by the Rhesus monkey oocyte from pyruvate and glucose was 12.77 and $0.73 \mathrm{pmol} / \mathrm{hr} /$ oocyte, respectively. Pyruvate is probably a major energy source for all early mammalian embryos.

\section{INTRODUCTION}

The importance of pyruvate to the early development of the mouse embryo was first demonstrated 5 years ago when it was shown that pyruvate, or a closely related compound, was needed for cleavage of the two-cell embryo (Brinster, 1965a). Subsequent studies using radioactive substrates have confirmed the importance of pyruvate in energy metabolism in both the mouse and rabbit embryo (Brinster, 1967a, b, 1968, 1969a). In addition, it has been shown that pyruvate is an important component of the culture medium for maturation of the mouse oocyte in vitro (Biggers, Whittingham \& Donahue, 1967) and probably also of the human oocyte (Kennedy \& Donahue, 1969). These findings have led to the suggestion that pyruvate may be the central energy source for development during the first few days for all mammalian species (Brinster, 1965b, 1969b).

Although the findings suggest a universal rôle for pyruvate as an energy source in early embryonic development, there is no definite information on the utilization of pyruvate in primate development. While it is difficult to obtain cleavage-stage embryos of primates for studies, small numbers of oocytes can be obtained from these species. Since it is probable that there is considerable similarity between the metabolism of the oocyte and the newly ovulated ovum, information obtained on the oocyte should be applicable to the newly ovulated ovum and to the zygote during the first few days of development (Brinster, $1969 \mathrm{a}, \mathrm{b})$. In addition, information about the utilization of pyruvate and glucose by a primate oocyte would be valuable in formulating a culture medium for the manipulation and maturation of oocytes in vitro. Therefore, the present studies on the ability of the rhesus monkey oocyte to oxidize pyruvate and glucose were undertaken. 


\section{MATERIALS AND METHODS}

The mouse oocytes used in the experiments were obtained by careful dissection of the ovaries of random-bred Swiss mice. The liberated oocytes, with their surrounding cumulus cells, were picked up and placed in an embryological watch glass containing $2 \mathrm{ml}$ of medium under $1 \mathrm{ml}$ of liquid paraffin. The medium used in the preliminary part of the experiments was Brinster's Medium for Ovum Culture-2 (BMOG-2) (Brinster, 1965a, 1969b). Monkey oocytes were obtained in the same manner except that the ovary was cut into quarters before dissection.

Cumulus cells were removed from the oocytes by a brief exposure to hyaluronidase at a concentration of 300 units $/ \mathrm{ml}$ in phosphate-buffered salt solution (Parker, 1961). This treatment removed the cells of the corona radiata from the mouse but not the monkey oocyte. Gorona cells were removed from the monkey oocytes by drawing the oocyte back and forth in a Pasteur pipette slightly larger in diameter than the zona pellucida of the oocyte. After the external cells were removed from the zona, the oocytes were placed in BMOG-2 for 10 to 15 $\min$.

Before use in the experiments, the oocytes were washed twice in $3 \mathrm{ml}$ of a medium containing no energy source (Brinster, 1967a). From the second wash, they were picked up in a volume of $2 \mu \mathrm{l}$ and deposited in a small droplet $(50 \mu \mathrm{l})$ of the medium under liquid paraffin in a tissue culture dish. From this droplet, the oocytes were moved in less than $1 \mu \mathrm{l}$ to a second droplet (25 to $30 \mu \mathrm{l}$ ) of medium containing the radioactive substrates. Finally, the oocytes were picked up from this second droplet in a specific quantity (usually $1 \mu \mathrm{l}$ ) of medium and deposited under three drops of sterile liquid paraffin in a serological test tube $7 \mathrm{~mm} \times 45 \mathrm{~mm}$. The tube with the oocytes was incubated, and the $\mathrm{CO}_{2}$ produced was determined by scintillation counting. The details of the procedure have been described previously (Brinster, 1967a). The only modification was that $100 \mu \mathrm{l}$ of phthalate buffer $(\mathrm{m} / 20, \mathrm{pH} 4)$ was used to stop the incubation instead of $1 \mathrm{~N}-\mathrm{H}_{2} \mathrm{SO}_{4}$.

The incubation medium containing the radioactive substrates was a modified Krebs-Ringer bicarbonate (Brinster, 1967a). The glucose was added to the medium at a concentration of $5 \cdot 6 \times 10^{-3} \mathrm{M}$. The specific activity was $3 \cdot 1$ $\mathrm{mCi} / \mathrm{mmol}$. The pyruvate was added to the medium at a concentration of $5 \times 10^{-4} \mathrm{M}$, and the specific activity was $29.5 \mathrm{mCi} / \mathrm{mmol}$. The concentrations of the radioactive substrates employed were based on the optimum conditions found in other experiments with early embryos (Brinster, 1965a, b, 1970) and oocytes (Biggers et al., 1967) of the mouse and rabbit, and are probably close to the optimum concentrations for monkey oocytes. In experiments with pyruvate, one oocyte was incubated for $4 \mathrm{hr}$ in $1 \mu \mathrm{l}$ of medium. In the experiments with glucose, ten to thirty mouse oocytes or five to ten monkey oocytes were incubated for 4 or $24 \mathrm{hr}$ in $1 \mu \mathrm{l}$ of medium.

\section{RESULTS}

The first experiments were performed using mouse oocytes. This allowed a comparison to be made between the micro-method used on the oocytes in these 
experiments with the macro-method previously used on one-cell unfertilized mouse ova (Brinster, 1967a). Since oxidation of pyruvate is greater, and therefore easier to measure, in one- and two-cell mouse embryos, media containing radioactive glucose were used in these first experiments in order to determine the limitations of the micro-method under the most stringent conditions. The results of the experiments are shown in Table 1.

The $\mathrm{CO}_{2}$ formed from glucose by the unfertilized mouse ovum is $0 \cdot 13 \pm$ $0.01 \mathrm{pmol} /$ ovum $/ \mathrm{hr}$ (Brinster, 1967a). This is not significantly different from the $0.145 \mathrm{pmol} / \mathrm{ovum} / \mathrm{hr}$ formed in a $4-\mathrm{hr}$ incubation by the mouse oocyte. Since it was expected that longer incubation times and fewer oocytes would have to be used in experiments with monkey oocytes, the oxidation of glucose by the mouse oocyte over a $24-\mathrm{hr}$ period was determined. The hourly rate of $\mathrm{CO}_{2}$ formation from glucose was significantly less when determined over a 24 -hr period than when determined over a 4 -hr period $\left(P<0.001, \mathrm{t}_{10}=\right.$ $5 \cdot 07$ ). Only about $4 \%$ of the total glucose present was oxidized during the $24-\mathrm{hr}$

TABLE 1

GARBON DIOXIDE PRODUCTION FROM GLUGOSE BY THE MOUSE OOCYTE

\begin{tabular}{|c|c|c|c|c|}
\hline \multirow{2}{*}{ Exp. } & \multicolumn{2}{|c|}{ 4-hr incubation } & \multicolumn{2}{|c|}{ 24-hr incubation } \\
\hline & $G^{*}$. & $G^{*} P$ & $G^{*}$ & $G^{*} P$ \\
\hline $\begin{array}{l}1 \\
2 \\
3 \\
4 \\
5 \\
6\end{array}$ & $\begin{array}{l}0 \cdot 113 \\
0.112 \\
0 \cdot 152 \\
0 \cdot 167 \\
0 \cdot 155 \\
0 \cdot 169\end{array}$ & $\begin{array}{l}0 \cdot 165 \\
0 \cdot 108 \\
0 \cdot 154 \\
0 \cdot 184 \\
0 \cdot 241 \\
0 \cdot 153\end{array}$ & $\begin{array}{l}0.039 \\
0.042 \\
0.048 \\
0.027 \\
0.035 \\
0.031\end{array}$ & $\begin{array}{l}0.099 \\
0.126 \\
0.108 \\
0.078 \\
0.151 \\
0.087\end{array}$ \\
\hline Mean \pm S.E.M. & $0 \cdot 145 \pm 0 \cdot 011$ & $0 \cdot 168 \pm 0 \cdot 019$ & $0.037 \pm 0.010$ & $0 \cdot 108 \pm 0 \cdot 010$ \\
\hline
\end{tabular}

Results expressed as pmol of $\mathrm{CO}_{2} /$ oocyte/hr. This value was calculated by dividing the total $\mathrm{CO}_{2}$ produced by the number of oocytes and the number of hours of incubation.

* Indicates radioactive substrate. G-glucose was the only energy substrate $\left(5.56 \times 10^{-3} \mathrm{M}\right)$. GP - a combination of glucose $\left(5.56 \times 10^{-3} \mathrm{M}\right)$ and pyruvate $\left(5 \times 10^{-4} \mathrm{M}\right)$.

In the 4-hr incubations, thirty oocytes were used per determination; in the 24-hr incubations, ten oocytes were used.

incubation period; therefore, a shortage of glucose could not account for the decline in metabolism of glucose seen in the longer culture period.

Cold pyruvate was added to the radioactive glucose medium to find out if pyruvate would increase the oxidation of glucose, particularly in the long incubation experiments. During the 4-hr incubation, there was a small increase in glucose oxidation which was not significant. During the 24-hr incubation, the inclusion of pyruvate in the radioactive glucose medium caused a significant increase in oxidation of glucose $\left(P<0.001, \mathrm{t}_{10}=6.97\right)$. However, the addition of pyruvate to the medium did not bring the hourly rate of glucose oxidation over a 24 -hr incubation up to the hourly rate found over a 4-hr incubation. The difference in the rates was significant $\left(0.05>P>0.01 ; \mathrm{t}_{10}=2.86\right)$.

In the experiments with the mouse, a minimum of thirty oocytes was needed for each determination when the incubation time was $4 \mathrm{hr}$. Since it was not possible to obtain so many monkey oocytes, it was necessary to use a longer 
incubation time for the oxidation of glucose in the monkey experiments. The results of these experiments are shown in Table 2. Even though a 24-hr incubation period was used, the oxidation of glucose was the same in the medium without pyruvate as in the medium with pyruvate, indicating that the 24-hr incubation with glucose alone was probably not detrimental to the monkey oocytes though it was to the mouse oocytes.

Oxidation of pyruvate was fifteen to twenty times greater than oxidation of glucose by the monkey oocyte, and the oxidation of pyruvate was not affected by the addition of cold glucose to the medium. About $10 \%$ of the available pyruvate was oxidized during the incubation. The results shown in Table 2 indicate that there was no interaction or interdependence between the oxidation of pyruvate and glucose by the monkey oocyte.

TABLE 2

CARBON DIOXIDE PRODUCTION FROM GLUCOSE AND PYRUVATE BY THE RHESUS MONKEY OOCYTE

\begin{tabular}{|c|c|c|c|}
\hline \multicolumn{2}{|c|}{ 24-hr incubation } & \multicolumn{2}{|c|}{ 4-hr incubation } \\
\hline$G^{*}$ & $G^{*} P$ & $P^{*}$ & $P^{*} G$ \\
\hline $\begin{array}{l}0.914 \text { (A9) } \\
1.458 \text { (G7) } \\
0.335 \text { (D5) } \\
0.642 \text { (F5) } \\
0.321 \text { (G6) } \\
0.681 \text { (J8) }\end{array}$ & $\begin{array}{l}0.621 \text { (B6) } \\
0.451 \text { (G5) } \\
0.776 \text { (E7) } \\
1.154(\mathrm{~F} 7) \\
1.138 \text { (H6) } \\
0.431(\mathrm{~J} 5)\end{array}$ & $\begin{array}{r}9.638(\mathrm{Al}) \\
18.281(\mathrm{Bl}) \\
12.651(\mathrm{Gl}) \\
9.650(\mathrm{E} 1) \\
13.830(\mathrm{Gl}) \\
12.595(\mathrm{H} 1)\end{array}$ & $\begin{array}{r}10.575(\mathrm{Al}) \\
9.954(\mathrm{Bl}) \\
15.488(\mathrm{Dl}) \\
12.342(\mathrm{Fl}) \\
9.169(\mathrm{H1}) \\
11.758(\mathrm{~J} 1)\end{array}$ \\
\hline$\uparrow 0.73 \pm 0.17$ & $0.76 \pm 0.13$ & $12 \cdot 77 \pm 1 \cdot 31$ & $11.55 \pm 0.92$ \\
\hline
\end{tabular}

Results expressed as pmol of $\mathrm{CO}_{2} /$ oocyte/hr. This value was calculated by dividing the total $\mathrm{CO}_{2}$ produced by the number of oocytes and the number of hours of incubation.

* Indicates radioactive substrate. G-glucose was the only energy substrate $\left(5.56 \times 10^{-3} \mathrm{M}\right)$. P-pyruvate was the only energy substrate $\left(5 \times 10^{-4} \mathrm{M}\right)$. GP-a combination of glucose and pyruvate.

In parentheses are the letter designation of the monkey and the number of oocytes used in the experiment.

$\uparrow$ Mean \pm S.E.M.

\section{DISGUSSION}

The first experiments, with the mouse oocytes, demonstrated that the rate of oxidation of glucose by the mouse oocyte was similar to the rate that had been found for the unfertilized one-cell ovum (Brinster, 1967a). This evidence supports the findings from culture studies in vitro where it was found that pyruvate but not glucose will allow development of the oocyte, one-cell ovum and twocell ovum (Biggers et al., 1967; Brinster, 1965a). These early stages appear to be remarkably similar in requirements. Technically, the first experiments showed that glucose oxidation decreased significantly when measured over a 24-hrincubation period, suggesting that in the longer experiments needed to study monkey oocytes, the estimates of glucose oxidation might be lower than the actual rate of oxidation. The addition of cold pyruvate to the medium largely prevented the 
loss of the ability of the oocyte to oxidize glucose. Perhaps the low values for glucose oxidation measured over a 24 -hr period were due to a general deterioration of the oocyte which was partially prevented by the pyruvate.

In the case of the monkey oocyte, the addition of pyruvate to the medium did not affect glucose oxidation, and this suggests that the 24-hr determinations should be quite accurate for measurement of glucose oxidation by the monkey oocyte. Perhaps this is because more glucose is oxidized by the monkey than by the mouse oocyte and is, therefore, able to supply more of the oocyte's needs when employed alone in the medium.

The most striking finding of these studies is that the monkey oocyte oxidized pyruvate to a much greater extent (some fifteen times greater) than glucose. The values for both pyruvate and glucose oxidation found for the monkey oocyte are similar to the values found for the rabbit unfertilized ovum (Brinster, 1968, 1969a), but two to five times greater than those found for the mouse unfertilized ovum (Brinster, 1967a, b). This is what might be expected on the basis of size, since the monkey oocyte is more nearly the size of the rabbit oocyte than the mouse oocyte.

The similarity between the three species in the degree to which they oxidize pyruvate and glucose provides additional evidence for the hypothesis that the need for pyruvate and the utilization of pyruvate may be universal among mammalian embryos, including primates, during the early days of development. Certainly other species should be examined, particularly the human, but there seems little doubt that the same general pattern of energy substrate utilization will be found for the early embryos of most, if not all, Eutherian mammals.

\section{AGKNOWLEDGMENTS}

Financial support for this research was from PHS Research Grant No. 03071 from the National Institute of Child Health and Human Development. I thank Miss Mary Ryans for her excellent technical assistance.

\section{REFERENCES}

Biggers, J. D., Whittingham, D. G. \& Donahue, R. P. (1967) The pattern of energy metabolism in the mouse oocyte and zygote. Proc. natn. Acad. Sci. U.S.A. 58, 560.

Brinster, R. L. (1965a) Studies on the development of mouse embryos in vitro. II. The effect of energy source. F. exp. Zool. 158, 59.

Brinster, R. L. (1965b) Studies on the development of mouse embryos in vitro. IV. Interaction of energy sources. F. Reprod. Fert. 10, 227.

Brinster, R. L. (1967a) Carbon dioxide production from glucose by the preimplantation mouse embryo. Expl Cell Res. 47, 271.

Brinster, R. L. (1967b) Carbon dioxide production from lactate and pyruvate by the preimplantation mouse embryo. Expl Cell Res. 47, 634.

Brinster, R. L. (1968) Carbon dioxide production from glucose by the preimplantation rabbit embryo. Expl Cell Res. 51, 330.

Brinster, R. L. (1969a) Radioactive carbon dioxide production from pyruvate and lactate by the preimplantation rabbit embryo. Expl Cell Res. 54, 205.

Brinster, R. L. (1969b) Mammalian embryo culture. In: The Mammalian Oviduct, pp. 419-444. Eds. E. S. E. Hafez and R. Blandau. University of Chicago Press, Chicago.

Brinster, R. L. (1970) Culture of two-cell rabbit embryos to morulae. F. Reprod. Fert. $21,17$.

Kennedy, J. F. \& Donahue, R. P. (1969) Human oocytes: Maturation in chemically defined media. Science, N.Y. 164, 1292.

Parker, R. C. (1961) Methods of tissue culture, p. 58. Hoeber, New York. 